\title{
Obtaining Extremely High Lift to Drag Ratios with Flexible-Wall Turbulence Control
}

\author{
Sumon.K.Sinha* and Jim Hendrix** \\ Sinhatech \\ 3607 Lyles Drive, Oxford, MS 38655, U.S.A..
}

\begin{abstract}
In flight sink-rate measurements of a Standard Cirrus sailplane verified 67-80\% increase in average best glide ratio $(\mathrm{L} / \mathrm{D})$ by treating $8 \%$ of the mean aerodynamic chord of the wing upper surface with a passive Flexible Composite Surface Deturbulator tape. Flow induced long wavelength travelling waves on the flexible surface of the Deturbulator, related to lowfrequency turbulence-producing eddies are periodically perturbed by ridges on the substrate. Flow visualization has verified that this attenuates turbulence and promotes a thin stagnant separated zone on top of the wing. This has resulted in best $L / D$ values over 100 for a 15-m span standard class sailplane. This exceeds performance levels achievable by the usual approach of maximizing the extent of attached laminar flow.
\end{abstract}

\section{Nomenclature}

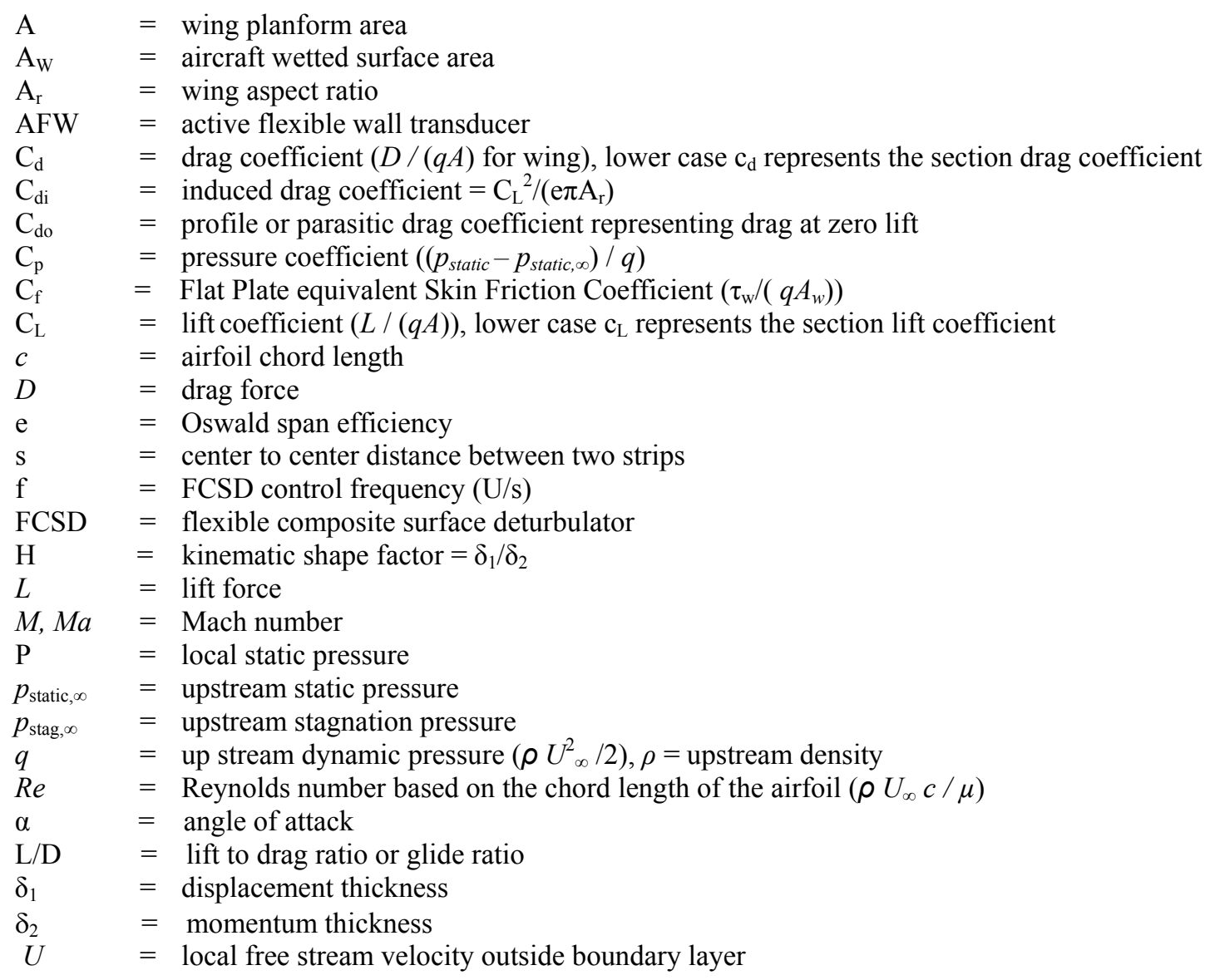

\footnotetext{
${ }^{*}$ President, Sinhatech, and Senior Member AIAA ${ }^{* *}$ Owner, Oxford Aero Equipment
} 


$\begin{array}{ll}U_{\infty} & =\text { upstream velocity } \\ u & =\text { fluid velocity in the stream wise direction } \\ v & =\text { fluid velocity normal to the stream wise direction } \\ x & =\text { distance from the leading edge along chord or streamwise coordinate for flow equations } \\ \mathrm{y} & =\text { wall normal coordinate for flow equations } \\ \tau_{\mathrm{w}} & =\text { wall shear stress }\end{array}$

\section{Introduction}

The lift to drag ratio or glide ratio is an important measure of aerodynamic efficiency of airframes and lifting surfaces. Maximizing L/D is beneficial for all fixed wing aircraft, from unmanned aerial vehicles and sailplanes to large commercial transport aircraft. Increasing the extent of laminar flow is deemed desirable for high performance wings. As a result, high-performance sailplanes representing the pinnacle of aerodynamic efficiency have fine tuned wing profiles to maintain laminar flow over the entire lower surface and from the leading edge to about $85-90 \%$ of the chord on the upper surface. This has culminated in modern 15-m wingspan standard-class sailplanes (without flaps) attaining a best glide ratio (L/D) of 48-50 with a wing aspect ratio around $22^{1}$. A sailplane with an aspect ratio 51.3 wing with flaps similarly optimized for extensive laminar flow has attained a best L/D of about $70^{1,2}$. However, are these limits intrinsic? Is it possible to obtain higher $\mathrm{L} / \mathrm{D}$ values without violating basic physical principles?

Typically, an increase in parasitic drag $C_{d o}$ overcomes reduction in induced drag $C_{d i}$ if the wing aspect ratio $A_{r}$ is increased. The normal strategy for minimizing parasitic drag is to maximize laminar flow while avoiding flow separation. This has been aggressively followed by sailplanes. An alternate strategy of keeping the boundary layer marginally separated while attenuating turbulent mixing was shown by Sinha ${ }^{3}$. In this paper, we present data which shows the extreme $\mathrm{L} / \mathrm{D}$ values that can be obtained with this technique.

The technique is based on the Flexible-Composite-Surface-Deturbulator or FCSD ${ }^{4-8}$ (Fig 1). Even though the Deturbulator (Fig 1) appears to be a manifestation of a "compliant wall", it is significantly different. Earlier compliant walls were aimed at damping instabilities in attached laminar boundary layers to delay transition or

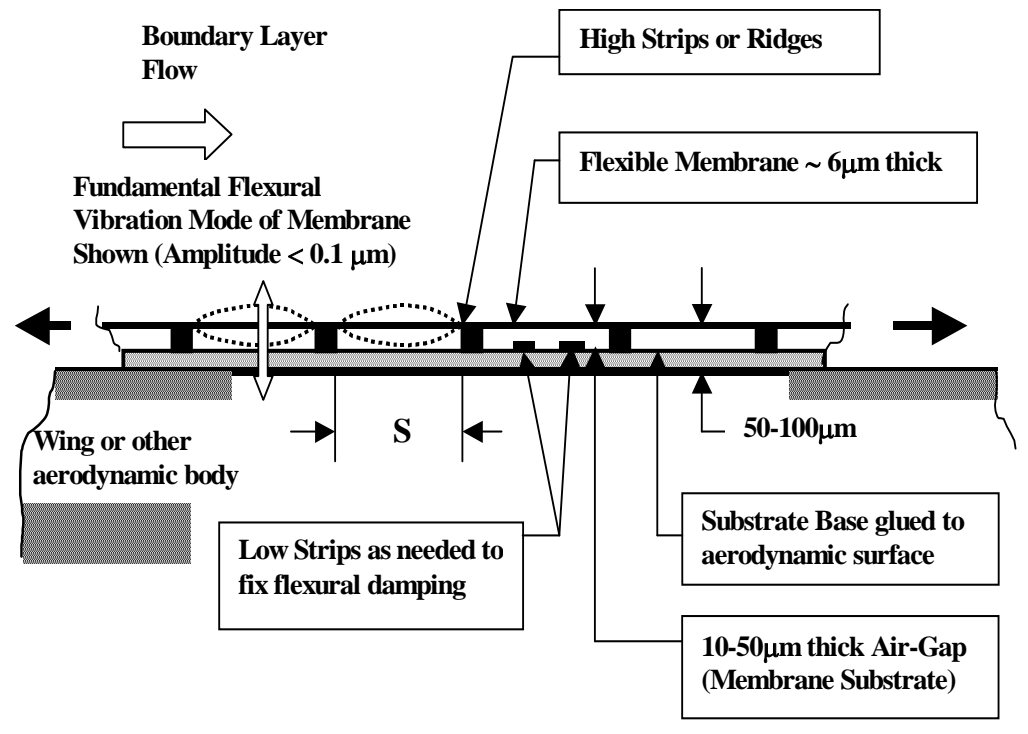

Fig 1. Schematic of the SINHA Flexible Composite Surface Deturbulator (FCSD)

counteracting wall-normal velocity components in turbulent boundary layers ${ }^{9-11}$. The precise matching of fluid and wall motion needed for this form of control has only been realized in experiments where controlled disturbances were introduced and subsequently annulled by the wall motion. Hence earlier experiments involving compliant or externally actuated flexible walls on attached and usually zero-pressure-gradient boundary layers have however failed to show appreciable repeatable drag reduction in real flows ${ }^{9}$. Additionally, devising compliant walls for lowspeed air flows has been considered impractical due to material property constraints ${ }^{11}$. The FCSD has overcome these constraints and succeeded since it relies on using a localized flow-device interaction to modify a non-zero pressure gradient flow with regions of marginal boundary-layer separation. It also does not rely on damping within its structure to attenuate turbulent fluctuations. 
The FCSD or "Deturbulator" modifies the turbulence spectrum by directly breaking down the larger turbulent eddies into smaller ones. This bypasses the normal turbulent cascade and can be used to attenuate turbulent mixing in regions of high shear. This stabilizes separated shear layers and enables thin and long non-dissipative closed separated regions over a significant extent of the chord (Fig 2). The separated region behaves as a "slip layer" by negating skin-friction and also provides a more cambered virtual shape to the wing profile as seen by the inviscid outer flow. As a result the section lift coefficient is also increased.

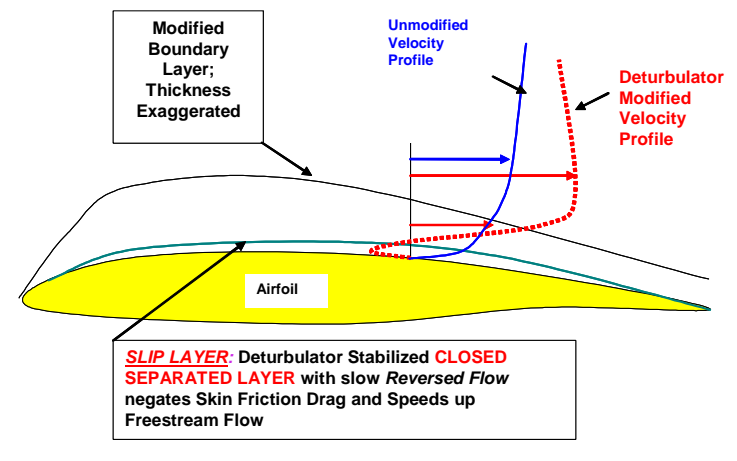

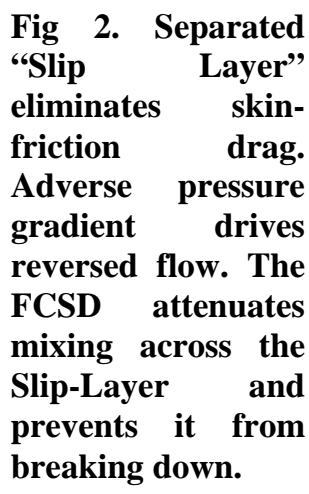

The Technology and Device: The SINHA$\mathrm{FCSD}^{4-8}$ is a thin (under $100 \mu \mathrm{m})$ passive (i.e., non-powered) device (Fig 1), consisting of a flexible membrane (typically $\quad 30-300 \quad \mathrm{~mm}$ wide) stretched across an array of strips on a substrate, running in the spanwise direction. The back of the substrate is bonded to the surfaces of

the wing or stabilizer, typically near the aft section of the airfoil for advanced low-drag wings, where marginal separation of the attached aerodynamic boundary layer leads to large increases in drag especially for high wing loadings. Under design conditions, the membrane of the FCSD undergoes extremely small (under $0.1-\mu \mathrm{m}$ amplitude) flow-induced flexural oscillations, which can neutralize turbulent fluctuations in the near-wall slightly separated boundary layer airflow (Fig 2a). The resulting modified boundary layer, which has an imbedded "slip layer" displays superior resistance to separation as compared to a laminar boundary layer (i.e., reduced $\delta_{1}, \delta_{2}$ ), while exhibiting lower skin-friction induced losses compared to either "naturally occurring" or artificially tripped turbulent boundary layers. This results in a reduction in wing profile drag. The current passive SINHA-FCSD concept evolved out of an earlier electrically powered Active Flexible Wall (AFW) boundary layer control concept $^{12-14}$ which has undergone extensive low-speed $(\mathrm{M}<0.15)$ wind tunnel testing at the University of Mississippi primarily for controlling unsteady flow separation ${ }^{13,15}$. Unlike earlier compliant and driven flexible wall devices which were typically tested on flat-plate zero pressure gradient flow ${ }^{9}$, the AFW and FCSD have been found to work only in boundary flows exposed to a varying streamwise pressure gradient. To understand the flowmembrane interaction mechanism the 2-D streamwise $\mathrm{u}$-momentum equation ${ }^{16}$ of the flow at the mean equilibrium position $(\mathrm{y}=0)$ of the surface membrane of the FCSD is considered first:

$$
\mathbf{v}(\partial \mathbf{u} / \partial \mathbf{y})_{\mathbf{y}=\mathbf{0}}=-(\mathbf{1} / \rho)(\partial \mathbf{p} / \partial \mathbf{x})+(\mu / \rho)\left(\partial^{2} \mathbf{u} / \partial \mathbf{y}^{2}\right)_{\mathbf{y}=\mathbf{0}}
$$

The streamwise $x$-component of velocity " $u$ " of the vibrating membrane (or the velocity of the fluid at the points of contact with the membrane) has been assumed to be negligible, while the wall-normal y-component of velocity " $v$ " of the fluid next to the membrane is clearly non-zero due to membrane compliance. Key to flow-membrane interaction is the realization that the wall-normal gradient of the streamwise velocity at the wall, $(\partial \mathrm{u} / \partial \mathrm{y})_{\mathrm{y}=0}$, can be extremely large at certain $\mathrm{x}$-locations. At such locations, even a small oscillation velocity $(\mathrm{v}<<\mathrm{U})$ of the flexible membrane can make the $\mathrm{v}(\partial \mathrm{u} / \partial \mathrm{y})_{\mathrm{y}=0}$ "control" term on the left hand side of equation (1) predominant enabling dynamic coupling of turbulent velocity fluctuations in the freestream with the FCSD. For a non-porous, noncompliant wall, this control term is identically zero. Additionally, if the boundary layer velocity profile at the aforementioned locations is such that prior to interaction $\partial^{2} \mathrm{u} / \partial \mathrm{y}{ }_{\mathrm{y}=0}^{2} \approx 0$, while $\left|(\partial \mathrm{u} / \partial \mathrm{y})_{\mathrm{y}=0}\right|>0$, (i.e., $\mathrm{u}(\mathrm{y})$ is approximately linear near the wall) an order of magnitude balance of the terms in equation (1) yields:

$$
\mathbf{v}(\partial \mathbf{u} / \partial \mathbf{y})_{\mathbf{y}=\mathbf{0}} \approx-(1 / \rho)(\partial \mathbf{p} / \partial \mathbf{x})
$$

Such a condition can be satisfied in boundary layers over curved surfaces, in the vicinity of $x$-locations where the streamwise pressure gradient $\partial \mathrm{p} / \partial \mathrm{x}$ changes from favorable $(\partial \mathrm{p} / \partial \mathrm{x}<0)$ to adverse $(\partial \mathrm{p} / \partial \mathrm{x}>0)$. The FCSD also passes oscillations with minimum damping at the control frequency ${ }^{4-8}$ : 
Fig 3 shows how large scale vortices, imparting long-wavelength traveling waves on the membrane of the Deturbulator, are broken down to smaller vortices of wavelength " $\mathrm{s}$ " corresponding to the frequency $\mathrm{f}$. Since $\mathrm{f}$ is closer to the "dissipation range" the smaller vortices are quickly smeared out by molecular viscosity and a large section of the normal step by step process of eddy breakdown ${ }^{17}$ through vortex stretching and bending is avoided. This attenuates turbulent mixing and entrainment across regions of sharp velocity gradients and helps stabilize the marginally separated boundary layer with its inflectional velocity profile as shown in Fig 2. The stabilized and nearly stagnant separated region acts as a slip-layer by keeping the fast moving outer flow off the wall. Fig $7 \mathrm{~b}$ shows an oil flow visualization of this layer.

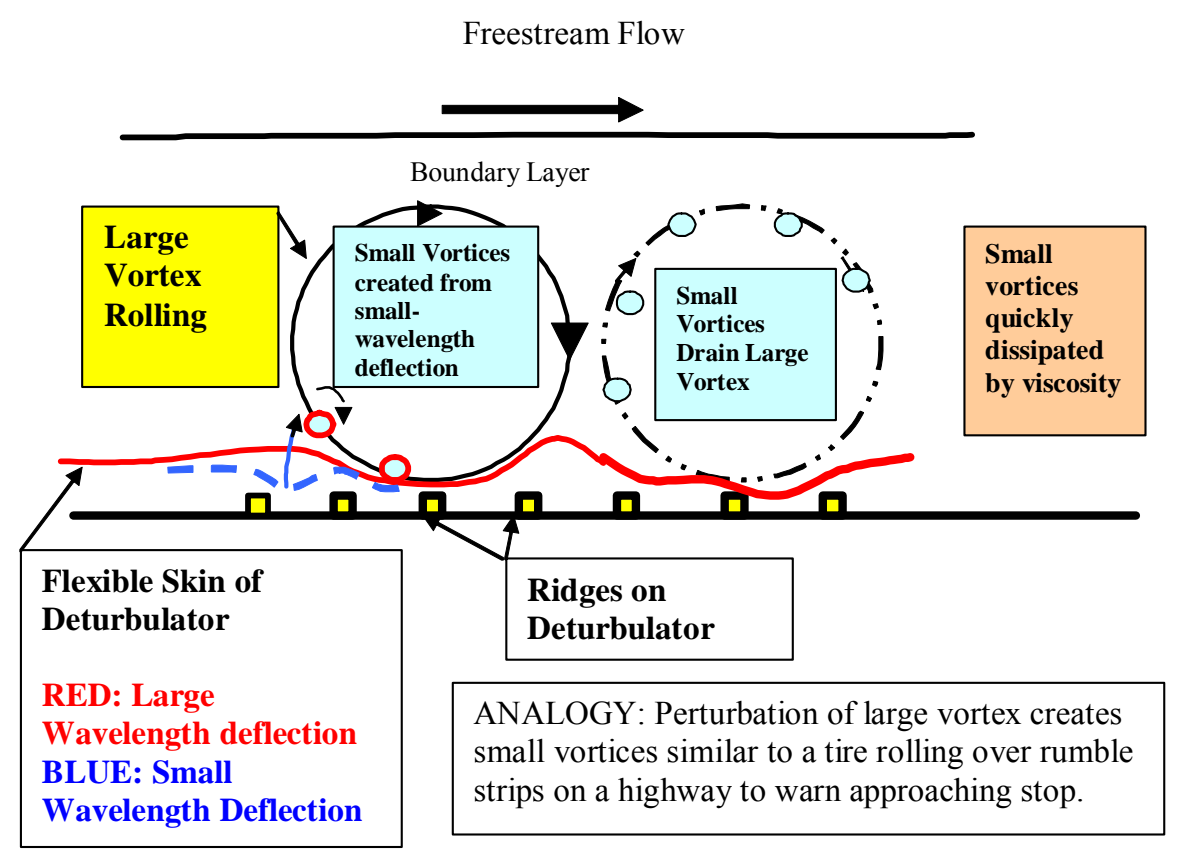

Fig 3. Sketch illustrating how the Deturbulator breaks up large vortices
The action of the Deturbulator is similar to vibrations transmitted to an automobile tire rolling over "rumble strips." The long wavelength traveling waves having a velocity $\mathrm{U} \quad(=\quad$ the freesream velocity) spawn smaller eddies as the troughs move past the ridges on the substrate. Since the ridges have a spacing $\mathrm{s}$, the smaller vortices occur at a frequency $f$ given by equation (1-b). The effect

of the smaller vortices is propagated back through the boundary layer to the freestream. Hence turbulence produced by the long wavelength low-frequency vortices is immediately broken down to the smaller vortices. Since the smaller vortices associated with frequency $f$ is closer to the dissipation range, the turbulence dies out. This slows down rapid mixing in regions of high shear ${ }^{16-17}$. The Deturbulator therefore behaves as a Large-Eddy breakup device as opposed to a damper.

Since the separated shear layer is prevented from thickening through turbulent mixing, increased form drag typical in separated zones is avoided. The skin-friction can be zero or negative over extended lengths, which is not attainable by maximizing attached laminar flow.

The Deturbulator can also reduce turbulence in larger separated regions, such as in bluff-body wakes. The quiescent separated wake behaves as a virtual streamlining extension and reduces form $\operatorname{drag}^{18}$.

For the dynamic interaction depicted in Fig 3 to exist and maximize as per equation (1-b), the Deturbulator tape needs to be located only within a certain receptive zone. This requires knowledge of the viscid and inviscid flow over the base airfoil and can be expected to vary with airfoil profile, Re, $\mathrm{M}, \alpha$ and surface irregularities. Additionally, the thickness of the Deturbulator tape itself modifies the airfoil profile and this effect can be utilized to encourage the boundary layer to undergo marginal separation as shown in Fig 4. If optimally done, the boundary layer on the surface of the Deturbulator remains attached while marginal separation extends both upstream to the leading edge and downstream to the trailing edge. On the upper surface of a wing depicted in Fig 4, this speeds up 
the inviscid freestream and increases the circulation, effective camber and section $\mathrm{C}_{\mathrm{L}}$. The Deturbulator tape needs to be wide enough to cover the excursion of the receptive zone across the desired range of airspeeds and wing loading. Additionally, the ridge spacing of the Deturbulator needs to be tailored such that the frequency $f$ is close to the dissipation range of the turbulence for the range of freestream velocities.

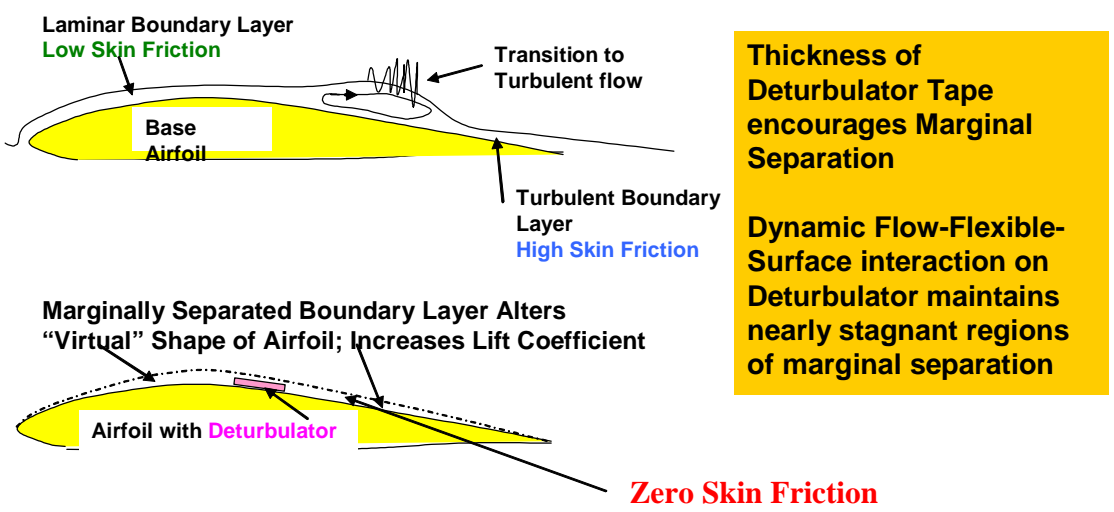

\begin{abstract}
Fig 4. How the Deturbulator encourages boundary layer separation and stabilizes the slip layer to virtually morph the camber of the airfoil while eliminating skin friction
\end{abstract}

\title{
II. Technical Approach
}

Details of the aforementioned phenomenological explanation are extremely difficult to observe due to submicron scales involved normal to the wall, along with scales about 5-orders of magnitude larger along the flow. These have to be indirectly inferred from larger scale measurements which do not upset the process. Much of the reasoning, such as the control frequency $\mathrm{f}$ and flow flexible-wall interaction physics is based on earlier wind-tunnel tests with the $\mathrm{AFW}^{12-14}$. Hence, a decision was made to proceed with flight tests to establish the overall validity of the FCSD system as opposed to resolving small-scale details of the constituent process first.

Early tests of FCSD patches on a NLF-0414F wing of a GT-3 all-composite trainer aircraft (manufactured by Global Aircraft, Starkville, MS) indicated $17-27 \%$ boundary layer momentum recovery on the top and bottom surfaces as measured in flight at $\mathrm{Re} \approx 5$-million ${ }^{4}$. Subsequent tests on the same wing showed profile drag reductions in the range of $12-25 \%$ at $\mathrm{Re} \approx 4$ to 6-million as measured with trailing edge mounted drag rakes ${ }^{5}$. Low-speed wind tunnel tests at $\mathrm{Re}=0.3$-million on the NLF-0414F airfoil showed the FCSD capable of reducing profile drag and enhancing lift in spite of separated flow near the trailing edge, resulting in a $12 \%$ enhancement in section L/D. In all these tests the Mach numbers remained below 0.16 .

Tests on the Standard Cirrus sailplane (manufactured in 1970 by Schemp-Hirth, Germany; shown in Fig 5) facilitated the optimum location of the Deturbulator tape since the wing root section airfoils, transitioning linearly from the Wortmann FX S 02-196 at the root to the Wortmann FX 66-17 A II-182 at the inner end of the aileron are capable of operating over a wider range of Reynolds numbers (0.2-4 million) without undergoing breakaway boundary layer separation. Also, the pressure distributions over these airfoils do not change drastically within this Re range even though laminar flow is maintained over about $30 \%$ of the top surface. Thus, low-speed wind tunnel results can be more readily extrapolated to flight conditions. Earlier papers by Sinha and Ravande ${ }^{5,6}$ describe test results, beginning with low-Re wind-tunnel tests of wing airfoil sections and culminating in treating the entire span of the wing to achieve $18 \%$ reported increase in best $\mathrm{L} / \mathrm{D}$ based on independent in-flight sink rate measurements by Johnson ${ }^{19}$. The focus of this work is on observable effects guiding the optimization procedure for installing the Deturbulator on the Standard Cirrus wing. These results are part of an ongoing developmental process aimed at increasing $\mathrm{L} / \mathrm{D}$ and $\mathrm{C}_{\mathrm{L}}^{3 / 2} / \mathrm{C}_{\mathrm{d}}$. 


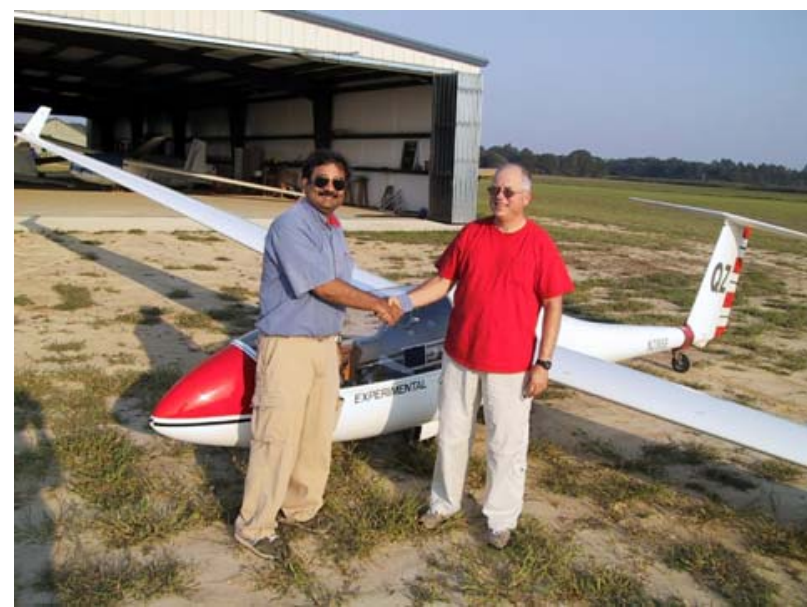

Fig 5. The Standard Cirrus, 15-m wingspan, single seat, all composite test sailplane

Initial flight tests ${ }^{6}$ were conducted with a 600 -mm long FCSD strip mounted on the lower surface of the wing of the Standard Cirrus. The strip was centered on the inboard section of the $15-\mathrm{m}$ span wing, $1.32-\mathrm{m}$ (53 inches) from the wing-fuselage joint. The $813-\mathrm{mm}$ chord wing section at this spanwise location is a linear transition from the Wortmann FX S 02-196 at the root joint to the Wortmann FX 66-17A II-182 at a spanwise location of 4.17-m outboard (beginning of ailerons). A wing-trailing edge mounted drag probe (rake) incorporating an array of total head tubes connected to a common header and encompassing $12.5-\mathrm{mm}(1 / 2$ ") of the wing top and bottom boundary layer at the trailing edge, was used to monitor changes in the wing wake. The top holes of the probe were plugged for bottom surface measurements and vice versa. A calibrated temperature compensated differential electronic pressure transducer was used to measure the difference between the stagnation pressure from the aircraft's pitotstatic probe and the integrated drag-probe stagnation pressure. The pressure transducer output (Volts) gives a direct indication of the profile drag from the wing bottom or top. A reduction in Voltage output indicated drag reduction. However, a lower surface Deturbulator also reduces positive camber and reduces section $C_{L}$.

Early tests on the upper surface at the 52-53 inch span station did not result in drag reduction. This prompted the wind tunnel studies described below.

\section{Wind Tunnel Setup}

The SINHATECH low-speed Wind Tunnel used in these tests has an entrance 4-ft high and 3-ft wide with an exponential contraction down to the 12-inch high, 9-inch wide test section. 127-mm chord, 190-mm span stereolithographed hand-smoothened and painted models of the 53-inch $(1.346 \mathrm{~m})$ span airfoil and tip airfoil (Wortmann FX 66-17 A II-182 outwards from 4.17-m span) of the Standard Cirrus wing section were tested. Various locations of the Deturbulator were screened using a 1-chord height wake rake placed $1 / 2$-chord behind the trailing edge. Tests were run at $\mathrm{Re}=300 \mathrm{k}$ and $\mathrm{M}=0.09$ over a range of $\alpha$ values.

\section{Deturbulator Tape and Installation:}

Test Deturbulator tapes for the wind-tunnel and flight tests were fabricated by SINHATECH using in-house prototyping facilities. The ridges (Fig 1) were 2-mm apart with a single row of low strips $15-\mu \mathrm{m}$ lower in between the high strips. These dimensions provide $\mathrm{f} \sim 7.5 \mathrm{kHz}$ to $25 \mathrm{kHz}$ for airspeeds between $15-50 \mathrm{~m} / \mathrm{s}$. A $6-\mu \mathrm{m}$ thick aluminized Mylar sheet, whose edges were either taped to the airfoil surface, or in the final design glued to the edges of the substrate, was used as the flexible membrane. The overall thickness of the FCSD tape was about $80-\mu \mathrm{m}$. The substrates had pressure sensitive adhesive backing and had widths varying from about 6-mm to 50 -mm and lengths from 150-mm to 500-mm depending on application. The FCSD strips were oriented with the ridges on the substrate running spanwise. Also, the cavity between the membrane and substrate (Fig 1) was vented to the freestream such that reduction in ambient pressure due to altitude and increased airspeeds did not lift the membrane off the ridges.

For the latest test reported here the original Mylar sheet was replaced with a flexible fiber reinforced composite having the same mass per unit area as the Mylar. The fiber reinforcements increased the tensile stiffness of the membrane and also increased its robustness. This has resulted in more repeatable performance. 
Flight Performance Tests:

These involved towing the sailplane to an altitude above thermal activity and maintaining constant indicated airspeeds during subsequent descent, while automatically recording altitude vs. time with a GPS based flight data recorder. The rate of descent yielded the sink rate from which L/D was estimated. Since vertical air mass movements can bias readings, an average of several readings is normally needed to derive stable $\mathrm{L} / \mathrm{D}$ values. However, when the L/D is not stable and real deviations are much larger than vertical air movements, individual measurements are justified and necessary to see true FCSD performance. Alternately, the test sailplane can be flown in parallel against another calibrated sailplane within the same air mass. Details of conducting tests, including instrument calibration are described in Johnson's article ${ }^{19}$.

\section{Results}

Wind tunnel tests on the 5-inch $(127 \mathrm{~mm})$ chord Standard Cirrus 53-inch span-section airfoil model were conducted at $\mathrm{Re}=0.3$ million and $\mathrm{M}=0.1$ with and without FCSD strips ${ }^{5,6}$. Surface oil flow patterns of the clean wing at an angle of attack $\alpha=-1^{\circ}$ indicated a separation bubble on both top and bottom surfaces (as the region

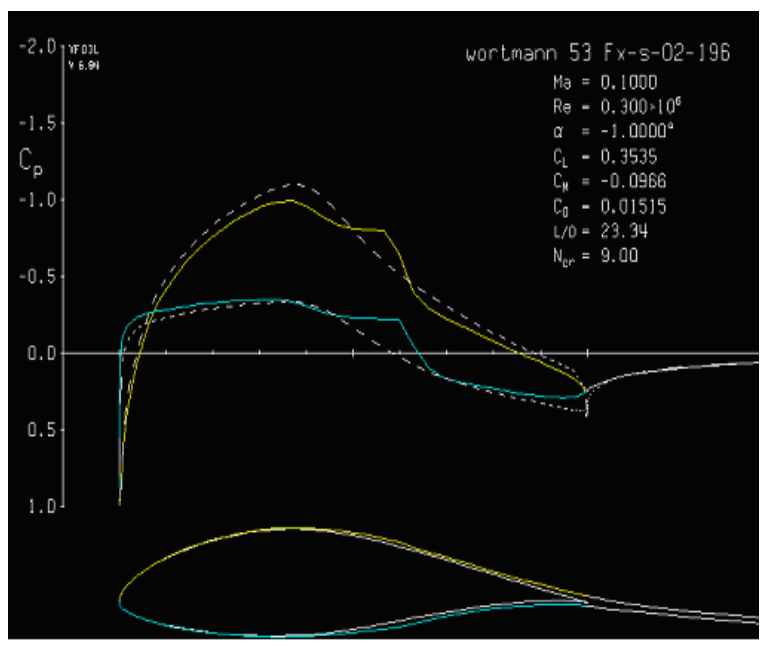

Fig.6. XFOIL Simulation of Flow on 5-inch Chord Wind Tunnel Model of Std. Cirrus 53-inch Span Airfoil Section showing $C_{p}$ Distribution on Suction (yellow) and Pressure (blue) Surfaces at $\alpha=-1^{\circ}, \operatorname{Re}=0.3$ million and $M=0.1$
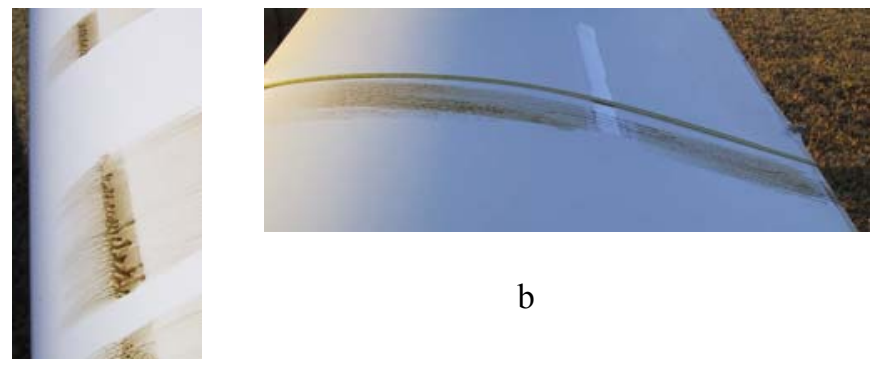

b

a

Fig 7. Oil Flow Visualization on Top Surface of the Standard Cirrus wing at the 53-inch Span Station (a) untreated; (b) with Deturbulator shown. where the oil accumulated). Even though the surface of the model had been slightly over-sanded, the positions of the separation bubble matched closely with those indicated in the surface pressure distribution plot in an $\mathrm{XFOIL}^{20}$ simulation for this airfoil under identical conditions shown in Fig 6. The separation bubbles are seen as bulges in the $C_{p}$ versus $x / c$ plot of Fig 6 . A variety of suction side FCSD treatments were screened for this airfoil model using the drag-rake measurements for $\alpha$ values ranging from $-2^{\circ}$ to $+2^{\circ}$ in steps of $1^{\circ}$. In all FCSD cases a nominal 6-mm $(0.25$ inch) wide substrate was employed with the Mylar membrane taped to the airfoil surface with $32 \pm 1 \mu \mathrm{m}$ thick Tesa tape (normally used for taping over wingfuselage joints in sailplanes). The location was based on applying the criterion of Equation (1a) as far as possible with adjustment for flow features unique to this situation.

Fig 7 shows oil flow visualizations on top of the wing with and without Deturbulator treatments at an indicated airspeed of 70-kt. This corresponds approximately to $\alpha=-1^{\circ}, \mathbf{R e}=\mathbf{1 . 5}$ million and $\mathbf{M}=\mathbf{0 . 1 1}$. The same $\mathrm{x} / \mathrm{c}$ location of the center of the Deturbulator strip was used was used for these flight tests as well. The untreated wing has a strong laminar separation bubble on the upper surface seen from the accumulated oil in Fig 7a, which 
ends in turbulent breakdown. The Deturbulator appears to remove the bubble, as turbulators or vortex generators do. However, a closer examination of Fig $7 \mathrm{~b}$ shows that the separated zone has not been removed, but extended from slightly behind the leading edge to the trailing edge as evidenced from the visibly stagnant oil layer (i.e., the slip layer). No turbulent breakdown resulting in rapid thickening of the oil is visible.

Fig 9 shows a full-span Deturbulator installation on the Standard Cirrus as tested by Johnson ${ }^{19}$ while Figs 10 and 11 show his sink rate and L/D polars based on sink rate measurements from averaging three Deturbulated and three clean-wing flights.

The 48 -kt calibrated airspeed point shows a persistent $18 \%$ improvement in $\mathrm{L} / \mathrm{D}$ that is well above the $4^{\text {th }}$ order polynomial fit through the data points. The minimum sink rate (at 37-kts) is $3.5 \%$ lower and remains almost

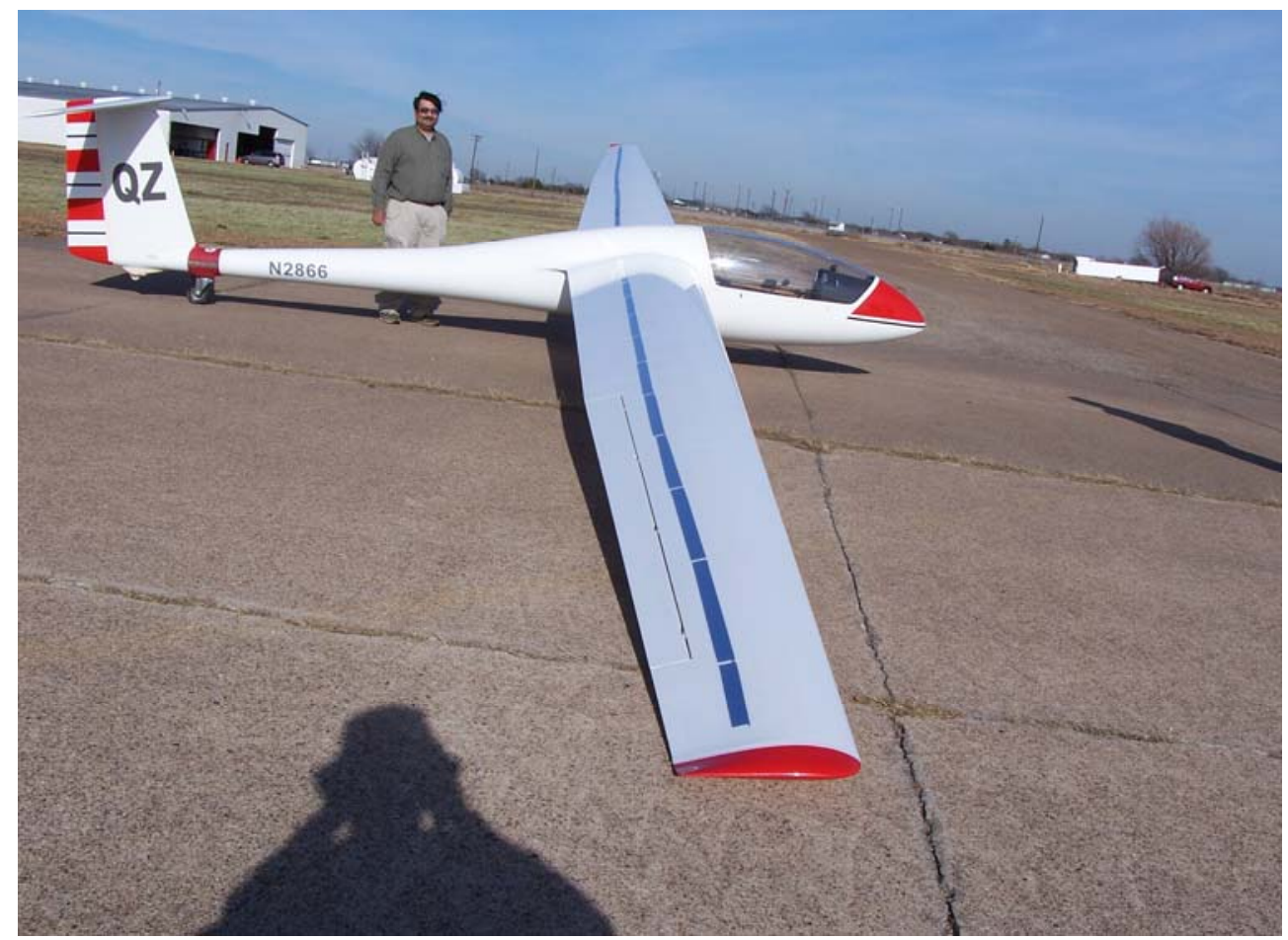

Fig 9. Full-Span upper surface Deturbulator on Std. Cirrus as evaluated by Johnson ${ }^{19}$. (50-mm wide Deturbulator Tape with Vents between 200-300 mm long segments)

unchanged till the point of maximum L/D. 
Std. Cirrus FLIGHT TEST MEASURED SINK RATE POLAR

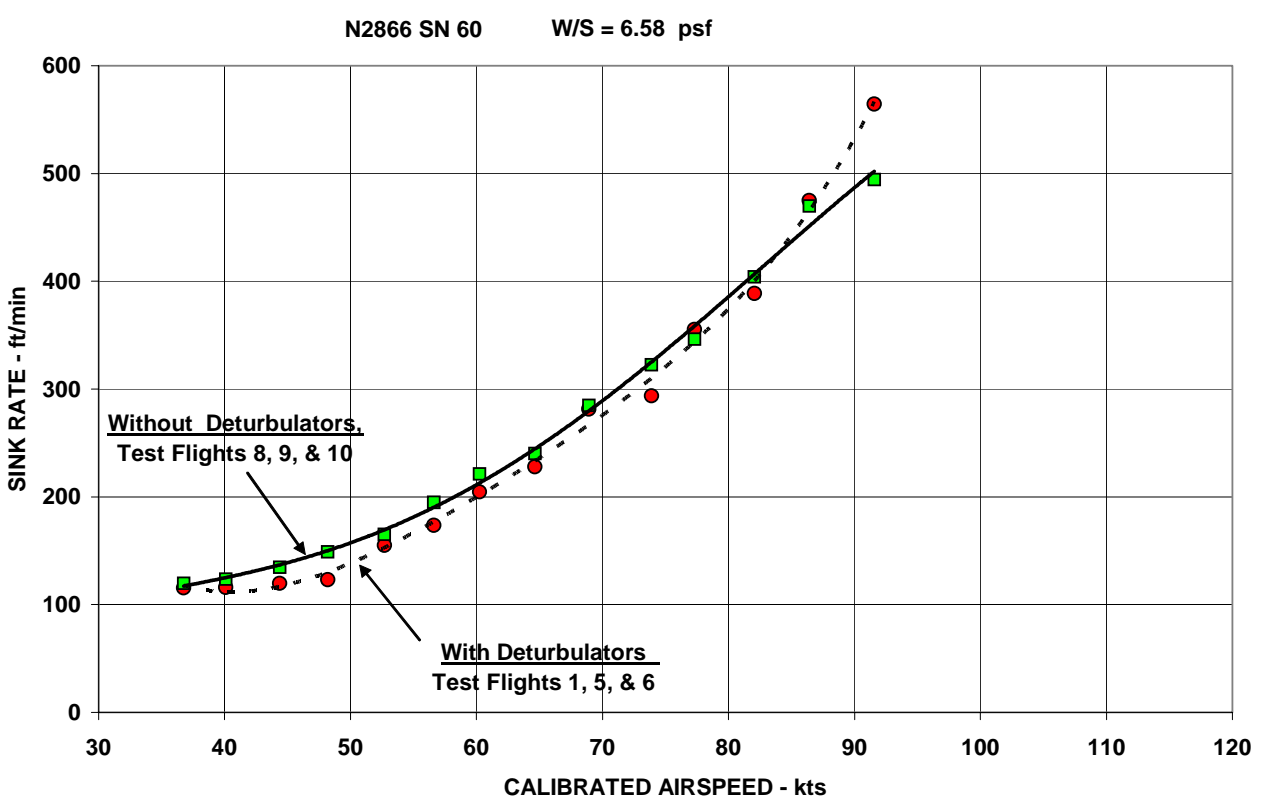

Fig 10. Measured Sink-Rates for Standard Cirrus with $4^{\text {th }}$ order fit trend lines (Johnson ${ }^{19}$ )

Std. Cirrus Flight Test Measured L/D Values

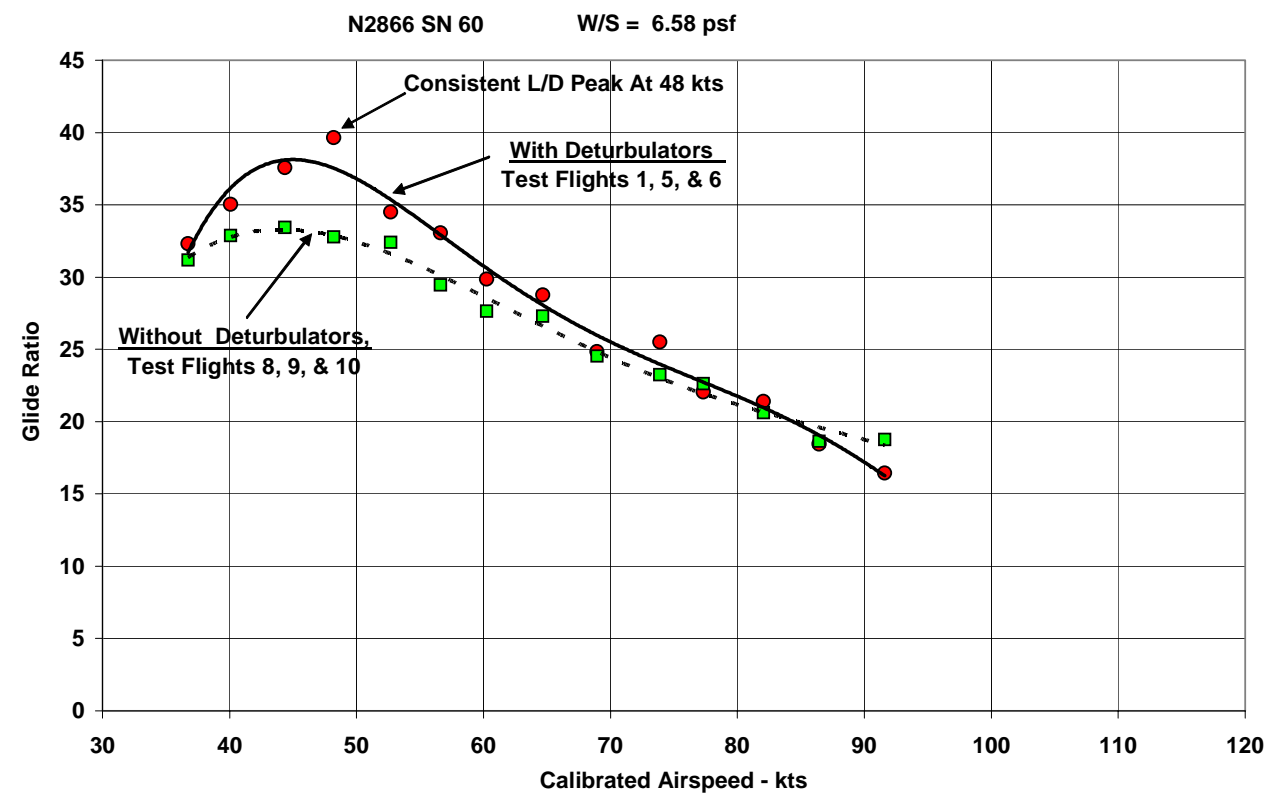

Fig 11. Measured L/D for Standard Cirrus with $4^{\text {th }}$ order fit trend lines $\left(\operatorname{Johnson}^{19}\right)$ 
The best L/D of 39.7 occurs at $48 \mathrm{kts}$ as opposed to a best L/D of 33.4 at $44 \mathrm{kts}$ calibrated airspeed.

\section{Is this the maximum that can be achieved for the Standard Cirrus?}

To answer these questions, Hendrix examined all of Johnson's flight recorder data and determined that L/D improved with each flight on a given day as the condensed water in the Deturbulator's air gap slowly evaporated with time. This was reported by Sinha ${ }^{3}$. The measured altitude versus time as well as sink rate and L/D polars derived from this data for Day -1 are shown in Fig 12. The performance of the Deturbulator at $48 \mathrm{kts}$ is seen to recover dramatically in Flights 3 and 4, which were discarded by Johnson as noise.

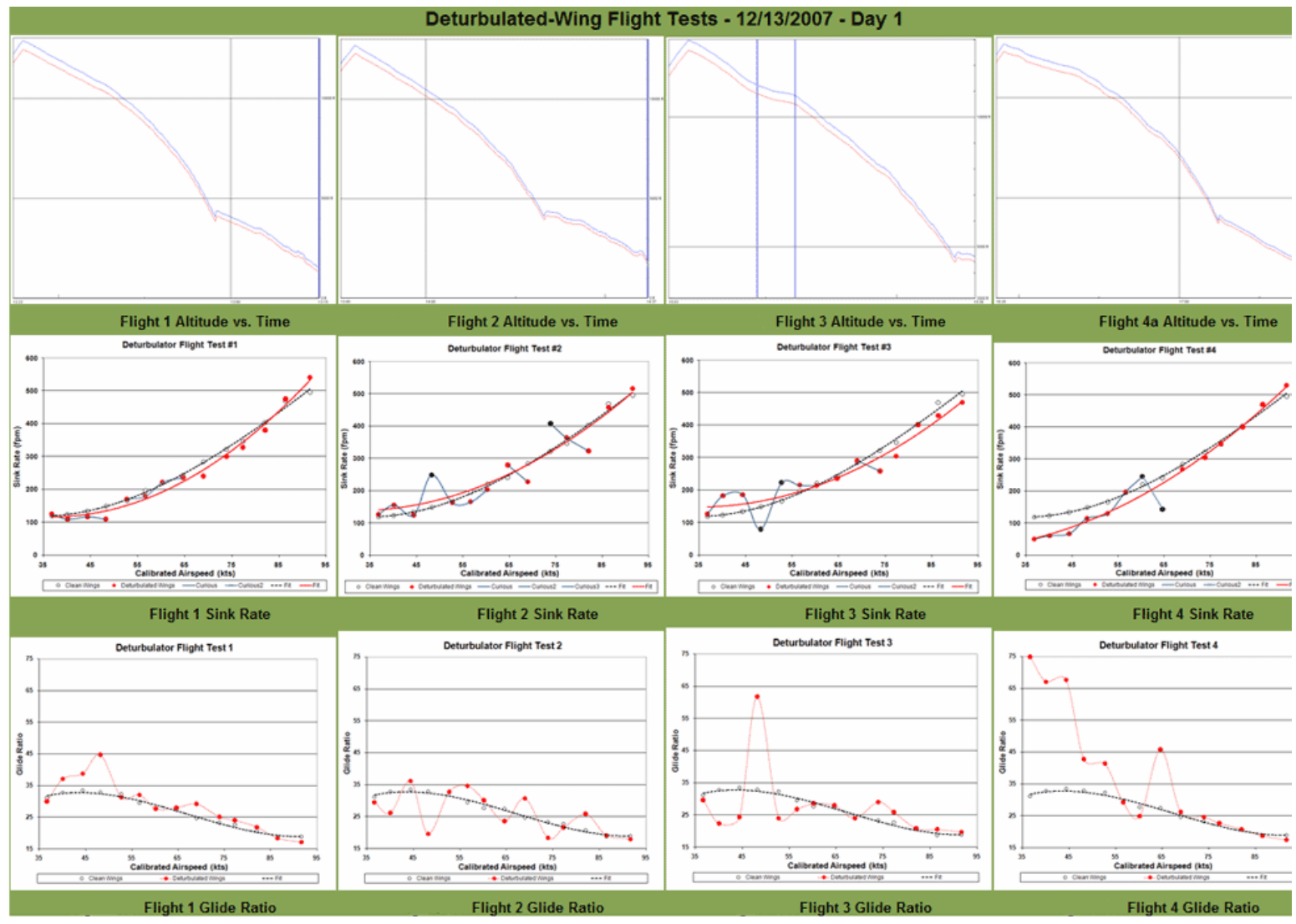

Fig 12. Altitude versus time (top row, blue-geometrical GPS altitude, red-pressure altitude), Sink rates (mid row) and L/D (last row) for Johnson's Flights 1-4 (left to right) on Day 1, with the Deturbulated Standard Cirrus (Red) versus clean wing (black). Note flattening out of low speed glide slope with progressive flights. Lines joining data points are simply to aid visualization and do not represent trends

\section{Did this represent the performance that can be expected if the Deturbulator works optimally?}

Fig 13 shows Glide Ratio polars from two different flights by two different pilots with two different Deturbulator applications on the same Standard Cirrus sailplane. The first (blue) curve is Johnson's Flight 3 with the original Deturbulator installation of Fig 9. The second (red) curve was obtained with Deturbulators with the new fiber-reinforced composite membrane flown a year later. Both polars exhibit nearly identical wavelike characteristics. It is extremely unlikely that this was due to weather or vertical air movement. Hence this clearly reveals the effect due to the Deturbulator. 


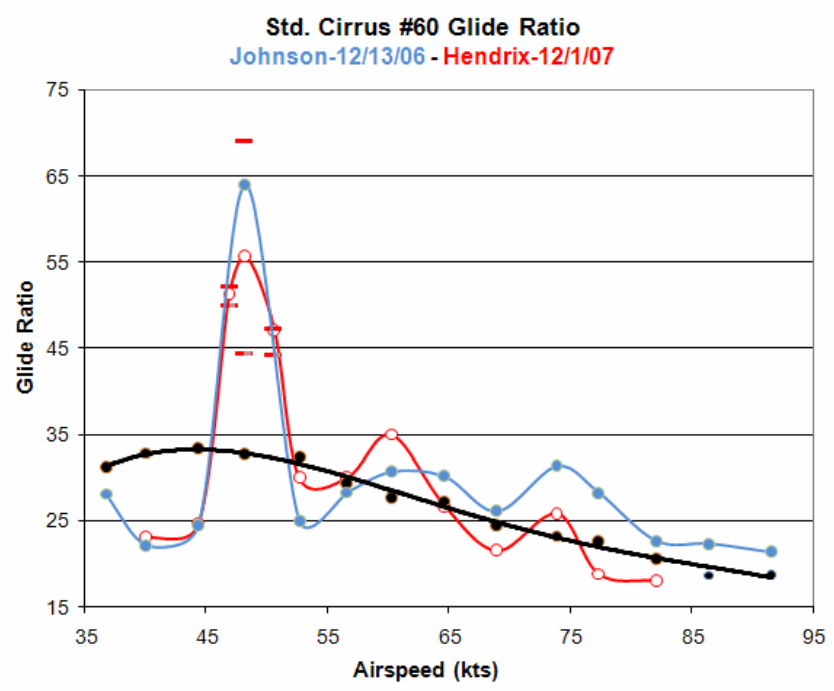

Fig 13. Glide Ratio versus Airspeed obtained on two different flights by two different pilots with two different Deturbulator applications on the same Standard Cirrus sailplane. The untreated wing polar is shown in black. Bars represent estimated uncertainties about measured data points.

Fig 14 shows surface oil flow visualizations at 50-kts indicated airspeed. The sailplane was launched, flown at 50-kts for about 10-minutes and landed. The photographs were taken immediately after landing. Besides showing marginally detached flow over most of the upper wing surface, an interesting feature in this image is the narrow band of thick oil immediately behind the deturbulator. This clearly shows that the flow does not reattach to the wing but skips off the deturbulator and within 6 centimeters reaches a separation distance such that it can no longer drag the oil on the wing surface. 


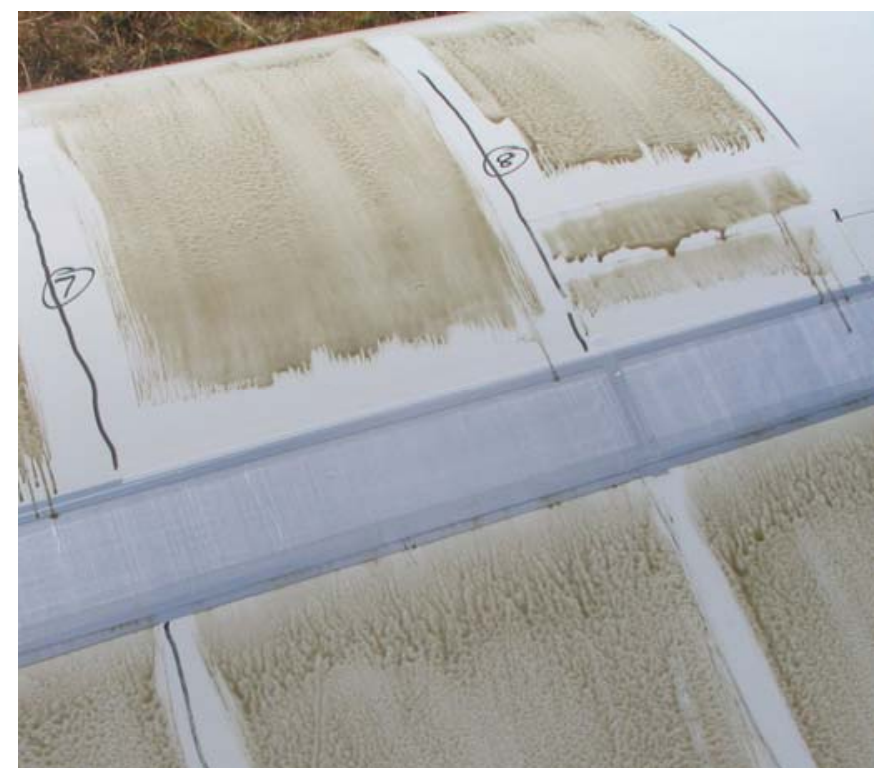

Fig 14. Surface oil flow visualization of the top surface of the Deturbulated Standard Cirrus wing (Left). The oil patch marked (7) is with a $30-\mu \mathrm{m}$ thick tape on the Leading Edge of the Deturbulator. The oil patch marked (8) is with two more $\mathbf{3 0}-\mu \mathrm{m}$ thick tapes upstream of the Deturbulator.

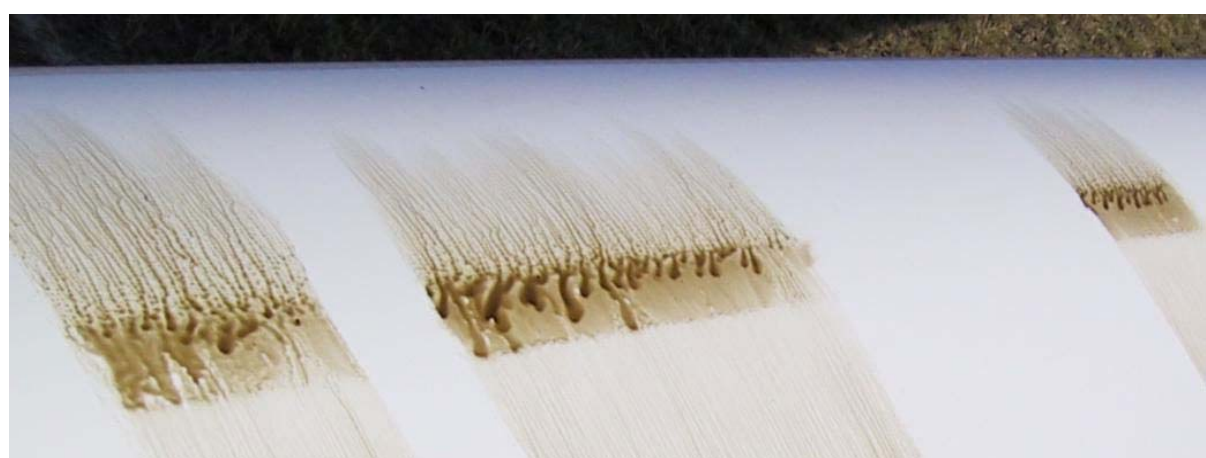

Fig 15. The flow around the same area of the untreated wing 


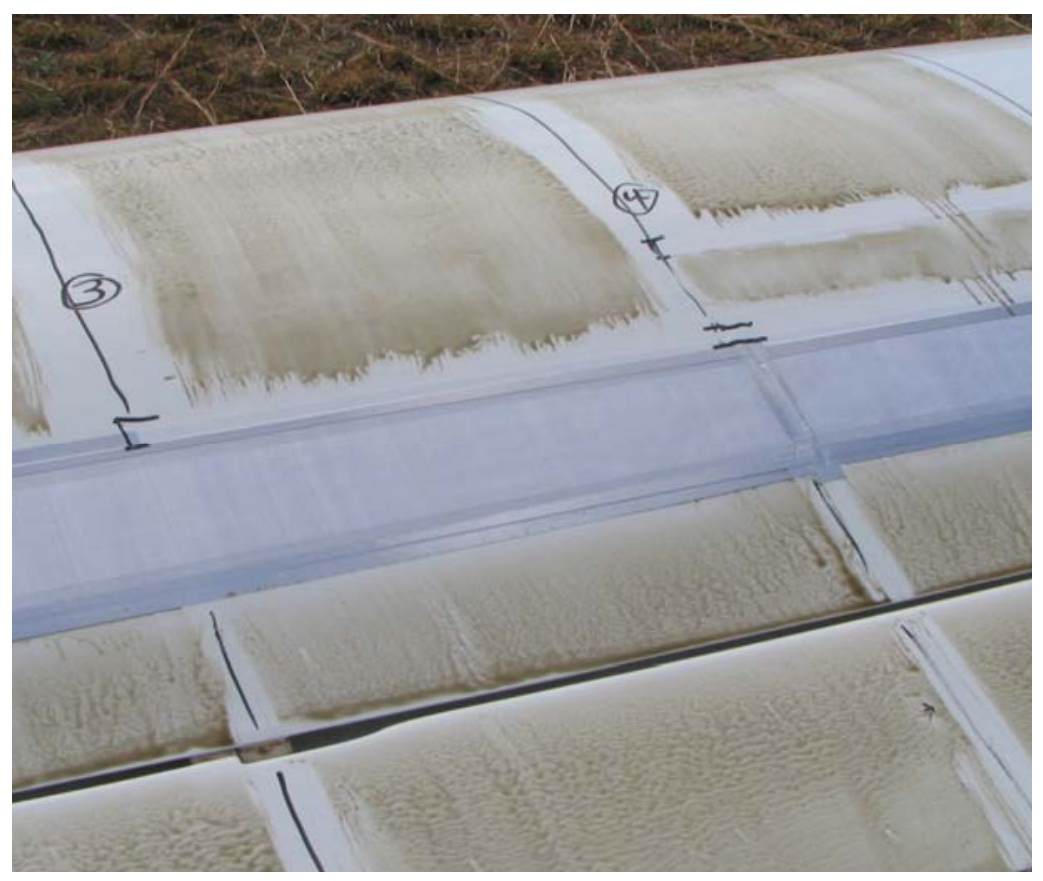

Fig 16. Surface oil flow visualization of the top surface of the Deturbulated Standard Cirrus wing near the ailerons. The oil patch marked (3) is with a 30um thick tape on the Leading Edge of the Deturbulator. The oil patch marked (4) is with two more $30-\mu m$ thick tapes upstream of the Deturbulator.

Areas of nearly stagnant layers of oil are seen upstream and downstream of the Deturbulator. This visually confirms the thin separated zones over most of the wing surface. A 30- $\mu$ m thick tape is clearly seen to impede the movement of oil downstream in the patch marked (8) in Fig 14. This shows the thickness of the boundary layer at about $30 \%$ chord at this span station of the wing which has a chord of about 1-m. Fig 16 shows reversed marginally separated flow on the ailerons and trailing edge of the wing. The aileron gap was sealed internally and below to prevent air flow from the bottom surface.

\section{Analysis, Discussions and Work in Progress}

One of the curious characteristics of the Glide ratio (L/D) polar is the wavelike pattern. Slight changes in airspeed are seen to cause large changes in L/D. This is believed to be caused by changes in locations of boundary layer separation and reattachment. The significance of this is that the boundary layer flow needs to re-attach on top of the Deturbulator for the $\mathrm{v}(\partial \mathrm{u} / \partial \mathrm{y})_{\mathrm{y}=0}$ "control" term conditions of Equation (1) to be non-zero. At the same time the condition of marginal boundary layer separation needs to exist upstream and downstream of the Deturbulator as depicted in Figs 4, 14 and 16. The separated zones need to be held in place by a balance between shear stresses in the separated shear layer and a non-zero pressure gradient. Hence, the Deturbulator cannot be expected to work on a flat plate with zero pressure-gradient everywhere.

When the Deturbulator works optimally the section $C_{L}$ increases since the stagnant separated zones increase the effective camber of the airfoil. This necessitates applying more down elevator to fly at the same airspeed. Each time the airspeed is changed the Deturbulator membrane needs to readjust to the changing static pressures by bleeding air through the substrate vents. This time lag is estimated about 20 -seconds and accounts for the gradual flattening out of each constant speed segment in the altitude versus time plot of Fig 17. If the pilot approaches the optimal airspeed with significant pitch momentum, the sailplane passes the optimal $\alpha$ and begins hunting about the ideal point. This behavior, shown in Fig. 18, is currently being analyzed. 


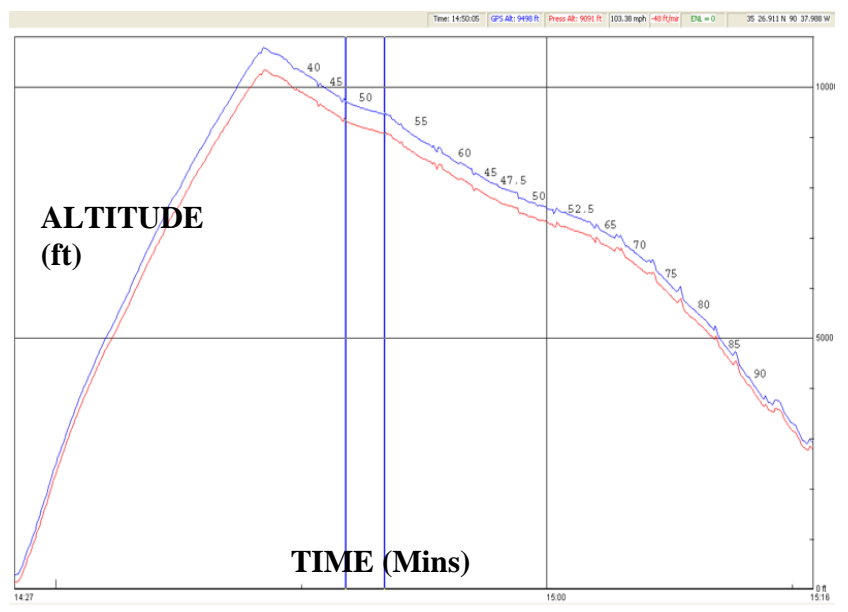

\author{
Fig 17. Altitude \\ (blue-pressure \\ altitude, red- \\ geometric \\ altitude from \\ GPS) versus time \\ for the test flight \\ by Hendrix, \\ Numbers \\ indicate constant \\ airspeed held \\ during segment
}

The 50-kts indicated airspeed clearly corresponded to the best L/D attainable. Fig 18 shows the L/D time trend at 50 kts indicated for Johnson's 12-13-06 flight (Fig 12, Flight 3) along with two flights by the co-author Hendrix a year later on 12-1-07. The 12-1-07 flight essentially repeats the features of Johnson's flight with a different Deturbulator with a fiber-reinforced composite flexible membrane (Figs 14 and 16) as opposed to a 6- $\mu \mathrm{m}$ Mylar membrane (Fig $7 \mathrm{~b}$ and Fig 9). The substrate ridges were also about 5- $\mu \mathrm{m}$ taller, creating less restrictive venting of the air gaps (Fig 1). The L/D values increase and level out at about 110 (Johnson) and 70 (Hendrix flight 1). It is important to note the similar trend shapes of Johnson's data and Hendrix' first $50 \mathrm{kt}$ measurement. Hendrix' data runs through the sequence twice as fast as the Johnson sequence, due to faster ventilation action because of deeper substrate channels. Also, the leveling of the L/D values at 70 is due to Hendrix flying slightly slower than the optimal airspeed for the new deturbulator and his $8 \%$ higher flying weight. This is indicated in Fig. 13, by neighboring measurements $2.5 \mathrm{kts}$ on either side of $50 \mathrm{kts}$ indicated, as well as the asymmetry of the curve fit. That the new, fiber reinforced deturbulator is capable of reaching the performance levels demonstrated by Johnson is seen in afore mentioned hunting behavior shown in Fig. 18.

The second flight by Hendrix shows the aforementioned oscillatory behavior with the L/D swinging periodically precisely between baseline performance and best values seen by Johnson a year earlier. At high L/D values a slight change in drag can have extremely influence on L/D.

It is worth mentioning that a $30-\mu \mathrm{m}$ thick tape was wrapped around the leading edge of the wing (Fig 20). This was to create a backward facing step immediate downstream of the stagnation point to facilitate lowering of skin friction through flow separation downstream of the step ${ }^{7}$. Fig 19 shows this also kept the flow on the bottom surface of the wing marginally separated even though only the upper surface was treated with the Deturbulator. Normally, the bottom surface of the Standard Cirrus wing has a strong separation bubble facilitating transition. Hence skin friction is significantly reduced on both surfaces of the wing. The Deturbulator is needed to prevent buildup of turbulence in the separated regions. The upper surface mounted Deturbulator appears to communicate with and mitigate disturbances originating at the lower surface.

The thick runs of oil, seen in Fig. 19, that stop within $12 \mathrm{~cm}$ of the leading edge show that the slip layer has reached a height such that the detached flow can no longer drag the oil with it.

Based on the analysis detailed by Sinha ${ }^{3}$ the theoretical best L/D for the Standard Cirrus is given by:

$$
(\mathrm{L} / \mathrm{D})_{\mathrm{Max}}=\left[\pi \mathrm{eA}_{\mathrm{r}}\left(\mathrm{A} / \mathrm{A}_{\mathrm{W}}\right) /\left(4 \mathrm{C}_{\mathrm{f}}\right)\right]^{0.5}
$$

Maintaining separated flow reduces the wetted area $A_{W}$ upon which the skin friction acts. Thus maintaining separated flow over $85 \%$ of the surface of the Standard Cirrus wing increased the best L/D from 33 to 65 . Fig 21 shows a plot of equation (2). The curve shows extreme sensitivity to the wetted area as L/D increases beyond 60 . Hence any small change in the efficacy of the Deturbulator leads to very large swings in L/D in this "extreme" L/D regime. Also, these L/D changes are not observed in flights without Deturbulators (e.g., baseline in Fig 11) ${ }^{19}$. 
Standard Cirrus \#60 Glide Ratio at 50 Knots Indicated 12/13/2006 Johnson (36 sec avgs) - 12/1/2007 Hendrix (28 sec avgs) 12/1/2007 Hendrix (2nd 50 kt run)

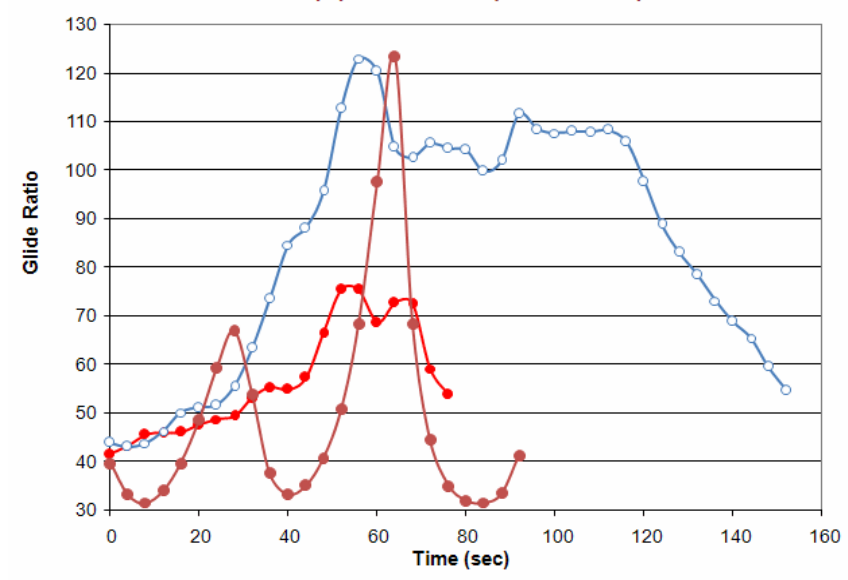

Fig 18. Close up of Glide Ratios at 50-kts indicated airspeed. Glide Ratios are computed by moving averages of GPS altitudes over 36 and 28 second periods.

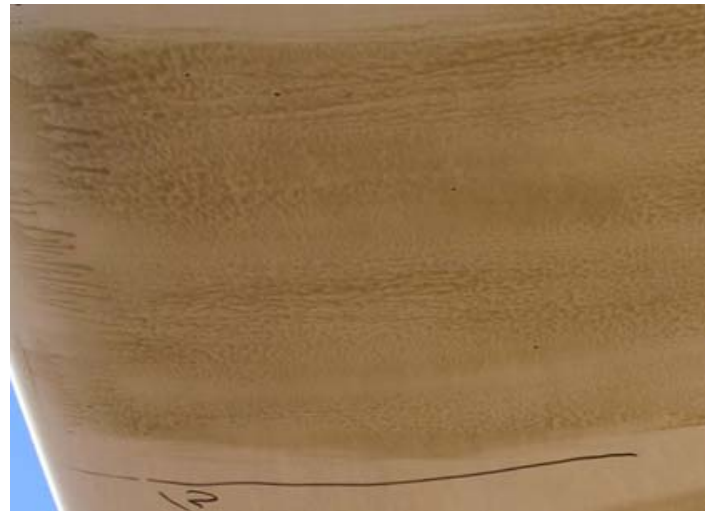

Fig 19. Flow on the bottom surface of the Standard Cirrus wing with Deturbulator treatment on the top surface. The flow is marginally separation and does not transition through a separation bubble.

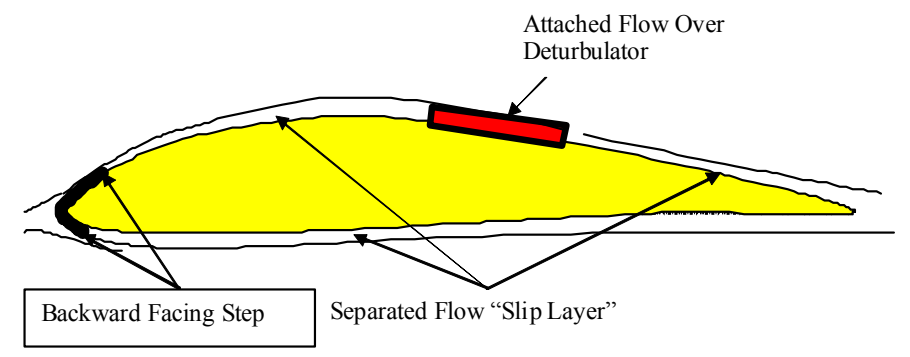

Fig 20. Schematic of tape around the leading edge to create backward facing steps encouraging separation in favorable pressure gradient portions of the flow 
L/D versus Wing Wetted Area Reduction

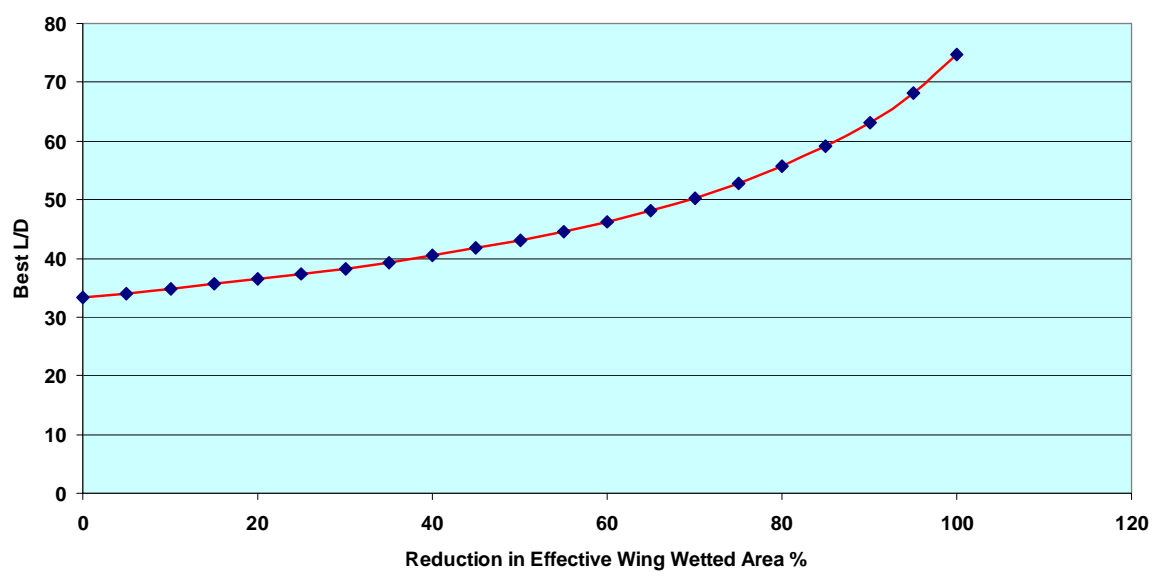

Fig 21. Variation of best $L / D$ with reduction in wetted area due to flow separation due to the Deturbulator as per Equation (2)

\section{Conclusions}

A passive flexible wall flow control device, the Deturbulator has been developed that can be affixed to selected $\mathrm{x} / \mathrm{c}$ locations on an aircraft wing surface to permit the boundary layer to separate but not break down through turbulent mixing. The Deturbulator converts large-scale turbulence producing vortices to smaller eddies, at a single high frequency. The smaller eddies are quickly dissipated. This bypasses the normal turbulence cascade.

The flow in the separated region is made nearly stagnant if the dynamic coupling is maximized between the flexible wall with fluctuations across the boundary layer at a point where the streamwise pressure gradient is close to zero.

In flight sink-rate measurements of a Deturbulator equipped Standard Cirrus sailplane verified that extreme enhancements in $\mathrm{L} / \mathrm{D}$ are feasible if the correct optimized conditions are maintained for the Deturbulator. $\mathrm{L} / \mathrm{D}$ values up to about 100 have been measured for a $15-\mathrm{m}$ span sailplane. This significantly exceeds best L/D values of all other sailplanes of any class, most of which employ aggressive laminar flow wings.

This condition requires the flow to be attached on top of the Deturbulator but marginally separated everywhere else. This can eliminate almost all skin friction and pressure drag attributable to the upper surface of the wing. The flow on the bottom surface of the wing was also marginally separated, thereby eliminating most of the bottom surface skin friction also. This occurred even though no Deturbulator was mounted on the wing bottom.

The time lag involved in the Deturbulator substrate vent's response to changes in static pressure is believed to be responsible for a wavelike behavior in the $\mathrm{L} / \mathrm{D}$ with time.

\section{Acknowledgments}

Acknowledgements are also due to the National Science Foundation (SBIR Award IIP-0638157) for supporting the development of the Deturbulator.

\section{References}

${ }^{1}$ Simons, M., 2005, Sailplanes 1965-2000, $2^{\text {nd }}$ Ed., EQUIP Werbung \& Verlag GmbH, Königswinter, Germany.

2 http://en.wikipedia.org/wiki/Glider

${ }^{3}$ Sinha S.K. “Optimizing Wing Lift to Drag Ratio Enhancement with Flexible-Wall Turbulence Control”, AIAA Paper No. 2007-4425, 25 ${ }^{\text {th }}$. AIAA Applied Aerodynamics Conference, June 25-28, 2007, Miami, FL, U.S.A..,

${ }^{4}$ Sinha, S.K., "Aircraft Drag Reduction with Flexible Composite Surface Boundary Layer Control," (AIAA 2004-2121), $2^{\text {nd }}$. AIAA Flow Control Conference, 28 Jun-July 1 2004, Portland, OR. 
${ }^{5}$ Sinha, S.K. and Ravande, S.V., "Drag Reduction of Natural Laminar Flow Airfoils with a Flexible Surface Deturbulator", AIAA Paper 2006-3030, $3^{\text {rd }}$. AIAA Flow Control Conference, San Francisco, CA, June 5-8, 2006.

${ }^{6}$ Sinha, S.K., and Ravande, S.V., "Sailplane Performance Improvement Using a Flexible Composite Surface Deturbulator," AIAA Paper 2006-0447, 44 ${ }^{\text {th }}$ AIAA Aerospace Sciences Meeting, Reno, NV, Jan 9-12, 2006.

${ }^{7}$ Sinha, S., and Sinha, S.K.,, "Method of Reducing Drag and Increasing Lift Due to Flow of a Fluid Over Solid Objects", International Patent Application No.: PCT/US2006/011430, International Publication Number WO 2006/105174 A2 with an International Publication Date of 5 October 2006.

${ }^{8}$ Sinha, S.K., "System and Method for Using a Flexible Composite Surface for Pressure-Drop Free Heat Transfer Enhancement and Flow Drag Reduction,” U.S. Patent No. 7,422,051, September 9, 2008.

${ }^{9}$ Bushnell, D.M. and Hefner, J.M., "Effect of Compliant Wall on Turbulent Boundary Layers," Physics of Fluids, Vol. 20, No. 10., Pt II, Oct 1977, pp. s31-s48.

${ }^{10}$ Dixon, A.E., Lucey, A.D., and Carpenter, P.W., "Optimization of viscoelastic compliant walls for transition delay", AIAA Journal, 32(2), pp.256-267, ISSN:0001-1452, (Feb 1994)

${ }^{11}$ Carpenter, P.W., Lucey, A.D., and Davies, C., "Progress on the use of compliant walls for laminar-flow control", Journal of Aircraft, 38(3), pp.504-512, ISSN:0021-8669, (May 2001)

${ }^{12}$ Sinha, S.K.; "System for Efficient Control of Flow Separation using a Driven Flexible Wall," U.S. Patent No. 5,961,080, October 5, 1999.

${ }^{13} \mathrm{Pal}, \mathrm{D}$ and Sinha, S., "Controlling Unsteady Separation on a Cylinder With a Driven Flexible Wall" AIAA Journal, Vol.36, No.6., 1998, pp. 1023-1028.

${ }^{14}$ Sinha, S.K.,., "Flow Separation Control with Microflexural Wall Vibrations," Journal of Aircraft, Vol.38, No.3., May-June-2001, pp. 496-503.

${ }^{15}$ Mangla, N.L., and Sinha, S.K., 2004, "Controlling Dynamic Stall with an Active Flexible Wall” AIAA Paper AIAA-2004-2325; $2^{\text {nd }}$ AIAA Flow Control Conf, Portland, June 28-July 1, 2004.

${ }^{16}$ Schlichting, H. , 1979, Boundary Layer Theory, McGraw Hill, New York, NY.

${ }^{17}$ Tennekes, H., and Lumley, J.L., 1989, A First Course in Turbulence, The MIT Press, Cambridge, MA

${ }^{18}$ Sinha, S.K. and Sinha, S.L., "Improving Automotive Fuel Efficiency with Deturbulator Tape" (Paper \#: 07APAC-15), Asia Pacific Automotive Engineering Conference, August 5-8, 2007, Hollywood, CA, USA, (to be presented).

${ }^{19}$ Johnson, R.H., 2007, "A Flight Test Evaluation of the Sinha Wing Performance Enhancing Deturbulators," SOARING and Motorgliding Magazine, The Journal of the Soaring Society of America Inc., Vol 71., No.5, May 2007, pp. 35-41.

${ }^{20}$ Drela, M., XFOIL: "An Analysis and Design System for Low Reynolds Number Airfoils (XFOIL 6.94, 18 December 2001)". Low Reynolds Number Aerodynamics, T. J.Mueller (ed.), Lecture Notes in Engineering, vol. 54, Springer-Verlag Berlin, 1989, pp.1-12.

${ }^{21}$ McCormick, B.W., 1995, Aerodynamics Aeronautics and Flight Mechanics, $2^{\text {nd }}$. Ed., John Wiley and Sons. 